\title{
Implementing eLearning Programmes for Higher Education: A Review of the Literature
}

\author{
Kayte O'Neill, Gurmak Singh, and John O'Donoghue \\ University of Wolverhampton, Wolverhampton, UK
}

\author{
kayte.oneill@uk.ngrid.com g.singh@wlv.ac.uk \\ j.odonoghue@wlv.ac.uk

\section{Executive Summary}

This paper is a consideration of the issues associated with the infrastructural aspects, pedagogic considerations and the need to associate the usefulness of technology to enhance the learning experience. This technological path will potentially enhance the learning process, not replace the lecturer or tutor. For lecturers and students, the implications of eLearning are extensive. Increasingly universities must provide quality and flexibility to meet the diverse needs of students - this will inevitably involve tailoring courses to suit differing educational needs and aspirations. Lecturers will be forced to fundamentally change their approach to teaching to accommodate the shift in student learning styles. The associated implication of increased workload requires proactive and effective management. Alongside this, eLearning threatens the fundamental structure of the university itself, as research forecasts that institutions cannot retain their traditional structure, in facilities and delivery via formal lectures and class based activity. It is clear that universities must change to accommodate demand and in response to new competition from global, giant corporate and virtual universities, however the problems associated with the change must be fully understood and taken into account prior to the transition taking place. Whilst the benefits of eLearning are highly prophesised, the many implications of implementing an eLearning programme require careful consideration. Getting it 'right' the first time will ensure long term success in a highly competitive market. Most, if not all the UK university sector are utilising technology to develop what they consider to be eLearning. Many of these implementations are costly and yet superficial, in terms of learner engagement and activity. They provide a content repository and in many cases limited active learner participation. For many students this results in endless reading of screen based text. When staff are 'forced' down the eLearning route as a consequence of management directives and mission statements the creation of sound pedagogic practice is often flawed or missing completely and activities constructed service the technology rather than student or learner progression or association.

Keywords: Higher education, eLearning, competitive environment, change, virtual, organisa-

Material published as part of this journal, either on-line or in print, is copyrighted by the publisher of the Journal of Information Technology Education. Permission to make digital or paper copy of part or all of these works for personal or classroom use is granted without fee provided that the copies are not made or distributed for profit or commercial advantage AND that copies 1) bear this notice in full and 2) give the full citation on the first page. It is permissible to abstract these works so long as credit is given. To copy in all other cases or to republish or to post on a server or to redistribute to lists requires specific permission and payment of a fee. Contact Editor@JITE.org to request redistribution permission. tional change, infrastructure, quality assurance, teaching and learning styles. 


\section{Introduction}

Education has become a commodity in which people seek to invest for their own personal gain, to ensure equality of opportunity and as a route to a better life (Davies, 1998). As a result, providers of Higher Education (HE) are finding themselves competing more than ever for students, funding, research, and recognition within the wider society. Whilst competition has always been an issue for universities, historically the focus was national rather than international. During the last decade and through the development of virtual education i.e. distance methods of delivery and new communication methods, HE has become 'internationalised'; providers are able to export themselves and as a result competition has been extended beyond national boundaries. Institutions which are actively seeking new markets and are able to utilise technological progress to structure themselves to deliver programs anywhere in the world are ideally placed to see their activities grow on a world-wide basis. However, for those who are complacent, the threat of being 'left behind' is significant. As the market continues to grow, new entrants will offer innovative worldclass solutions at low cost ("Lifelong learning," 1998) - making it impossible for the 'static' or 'complacent' providers to compete. Despite this seeming urgency, professed by many, US Economist ("Lessons of a virtual timetable,"2001) stresses the dangers of 'jumping on the bandwagon' too soon or without due diligence, explaining that, “The extension of an institution's brand is not without risk. Increasing the number of students who claim to have studied there can damage a university's reputation if those students do not receive the level of teaching that the university's name was built on."

Following on this argument, Pollock and Cornford (2000) acknowledge that in the implementation of eLearning, institutions will bear the risk of destroying those processes that offer important forms of support to students. Ultimately, it is possible that standardising a number of informal support systems will create competitive disadvantage - exactly the opposite to what the process sets out to achieve. Thus, HE institutions need to consider the implications for everyone involved before implementing any new eLearning strategies.

Universities need to consider cost-effective and efficient methods of operation if they are to survive. While technology alone might not be the answer to all of the university's problems, according to Daniel (1996), it certainly can play a key role. The benefits of utilising technology, particularly for developing online collaborative activities are well documented (Redfern \& Naughton, 2002). Relationships can also be fostered within the context of an online environment. Technology is a powerful medium particularly for part time work based students who find erratic attendance requirements and study difficult (O’Donoghue \& Singh, 2001).

The implications are clearly multi-faceted. The institution will itself necessitate change both physical, cultural and managerial. Students will require support in adapting to a potentially unfamiliar learning context. Finally the implications are immense for staff who are under pressure to introduce and develop often radically different approaches to their teaching and delivery.

\section{Structural Issues for Traditional Universities}

\section{Meeting the Changing Demand}

The rapid growth in eLearning, experienced particularly during the 1990s, has overcome many of the barriers to Higher Education (National Committee of Enquiry into Higher Education, 2001b), providing traditional universities with an opportunity to meet the changing worldwide demand for education. According to Goddard (1998) the demand for higher education is expanding exponentially throughout the world and by 2025 as many as 150 million people will be seeking Higher 
Education. This increase in demand is widely attributed to the changing culture of employment, where a job for life is no longer the norm, and to the advent of the so-called 'knowledge-driven society' (Katz, 2001). Society requires higher levels of skills and qualifications to fill the same 'worthwhile' jobs (Davies, 1998), and individuals see education as a status provider (Pritchard \& Jones, 1996. Volery and Lord (2000) point to the capacity constraints and resource limitations that can be overcome through the implementation of eLearning, creating a new opportunity to satisfy this growing demand.

The growth in demand will be a transition in the type of students undertaking higher education. The educational needs of individuals are now seen to be continuous throughout a working life, as labour markets demand knowledge and skills that require regular updates. A phenomenon of 'lifelong learning' has begun and according to Davies (1998) this new concept is quickly gaining social and political recognition as Governments recognise the positive impact of education on the health and growth of modern economies. Consequently, higher education institutions will be required to provide for a more diverse student body. In particular, eLearning will provide for the significant growth in the mature student market.

A recent report by the National Committee of Enquiry into Higher Education (2001a) reports that currently, more than $50 \%$ of HE students are mature students (someone who starts a degree aged 21 or over). This figure is set to increase as online learning and virtual universities allow educational experiences to be tailored to the needs of individuals or groups of individuals. Other social groups, such as those from remote areas, those with family commitments and those with disabilities will also add to the diversity of the new student body as the physical and temporal obstacles to Higher Education are removed with the help of technology (University of Leeds, 2001).

There is significant body of research that argues eLearning is not the only way to meet the changing demand for Higher Education. Hoare (2001) and Education and Training ("Lifelong learning," 1998) propose that modern economies rely on lifelong learning to fulfil demand for new knowledge, abilities and capabilities. However, Cooper (1999) does not believe that eLearning can sufficiently provide lifelong learning for everybody. Many of the students of a virtual university will not have the skills to learn independently and, consequently, it is unlikely that they will be successful in an eLearning environment. Instead, foundation courses must be provided locally and delivered face to face for those who need them. Such findings imply that the implementation of eLearning by traditional universities will not be the answer to the problem of changing demand. However, most innovative Higher Education institutions can make use of opportunities derived from technological progress to offer lifelong learning to many, and thus can contribute to the fulfilment of the needs of a diverse consumer base.

\section{The Competitive Environment}

The growing diversity of the Higher Education population must be matched by the offerings of universities as students demand more of their knowledge providers. A report by the National Committee of Enquiry into Higher Education (2001a) states. "a system growing and responding to the needs of an increasingly heterogeneous group of students must work actively to maintain its diversity and offer choice to intending students”. Volery and Lord (2000) claim that those universities that do not embrace the opportunities presented by technological developments will be left behind in the race for globalisation. Goddard (1998) agrees that the competitive environment is changing, as diversity in demand presents opportunities for new entrants to the market:

Universities have always had rivals, but the provision of learning is increasingly shared between academic and work/community environments. There has recently been a growth in corporate and virtual providers in the UK and abroad, which will pose chal- 
lenges and opportunities for universities in the future. It is clear that competition and potential collaboration in knowledge provision is becoming increasingly global.

Other research (Currie, 1999; Johnston, 2001; Paton, 2001) echoes Goddard's (1998) view that eLearning provides opportunities for new entrants into the Higher Education market. Goddard proposes that traditional universities implementing eLearning will face competition from two main rivals: corporate universities and virtual universities. Corporate universities present possibly the biggest threat to traditional institutions in their facilitation of lifelong learning. Six UK businesses have now established universities offering qualifications from National Vocational Qualifications (NVQs) to PhDs. According to Hoare (2001), the impact of eLearning on the world of business has been significant, particularly in meeting the needs of 'time poor executives' who cannot be out of the office for five days whilst still running their business. This type of competition represents a challenge for traditional universities. Implementation of an eLearning strategy must offer the same benefits as a corporate university or else be at a competitive disadvantage when recruiting graduates into postgraduate courses. Virtual universities present slightly different competition issues, mainly involving the potential to overcome international boundaries and recruit students from around the world. The University of Phoenix, one of the largest virtual universities in the world has 48,000 students, most of which are in full time work (Goddard, 1998). According to Currie (1999) students will be able to demand learning when and where they want it through virtual universities. As they can and will go to global providers for this, it will become more difficult to protect the reputation of traditional UK providers.

\section{Organisational Structure}

For traditional universities, a move towards virtual learning requires a fundamental change in the structure of the institution. A growing number of Higher Education institutions now exist only in cyberspace (Brewer, 1998) whilst for many students, the virtual learning experience is an online learning program sponsored by an established university or in some cases an online module which contributes to a degree that will be completed in a classroom setting. In any case, the transition from one type of structure to another represents an obstacle which must be negotiated with caution. As traditional universities endeavor to move from the didactic classroom or lecture based mode of delivery into technology supported learning, there is a need for academics, managers and policy makers to appreciate need for the changing landscape of higher education. Pollock and Cornford (2000) identify some essence of a possible 'vision' of non-campus based learning activity. "A decrease in the importance of the campus as students login from a distance to access 'courseware', new media technologies replacing traditional lectures, courses being delivered and accessed over the internet, promising to make higher education available anywhere and anytime”.

Pollock and Cornford (2000) propose that although visionaries believe that the virtual university solves the 'increasingly demanding problems of higher education', achievement of this vision is unlikely as the virtual university works in theory, but not in practice. Consequently, it is important for universities to understand the problems associated with the transition from traditional to virtual and to take account of such difficulties when making fundamental changes to the structure of the institution.

\section{The Implications of eLearning for Students}

\section{Adapting to a Change in Learning Processes}

It is widely acknowledged that implementation of eLearning leads to a fundamental shift in learning styles; however research into the effects of this shift is inconclusive. Singh and Priola (2001) 
summarise a number of opposing views. Firstly, Knight (1996) proposes that eLearning will benefit students who are used to being 'spoon fed' on the basis that students can no longer be passive about their learning. This view is endorsed by Hawkes and Cambre (2000) who claim that in order to gain results, students must take responsibility for their own learning. Secondly, and in contrast to Knight, the views of Kershaw are noted. Kershaw (1996) proposes that students will not automatically become conscientious, self motivated individuals and that success in fact depends on the level of interaction between students and lecturers that is required to stimulate good results. Based on the lack of conclusive evidence relating to the effects of a change in learning style, it seems appropriate to assume that not all students respond well to an eLearning environment. Cooper (1999) points out that independent learners have the potential to be successful in distance education, however those lacking in the skills to study independently will not react well in a virtual environment. Under such circumstances, institutions implementing eLearning must be aware that students will react differently to the changing paradigm of learning and rather than implement changes across the board, should aim to offer courses tailored specifically towards the different learning styles. In failing to take such action, universities run the risk of low success rates and at worst, failure.

\section{Dealing with the Isolation Issue}

The issue of isolation caused by eLearning has sparked a rigorous debate amongst researchers. The lack of interaction associated with eLearning is of prime concern to Cooper (1999) who remarks, "electronic contact cannot currently sustain the qualities and multi-dimensionality of the kind of tutor-student relationship that real learning seems to require"(p.xxvi). This opinion is further supported up Bourner and Flowers (1997) who suggest that if technological developments are to be incorporated into higher education, this should be accompanied by increased human contact.

In a recent panel discussion (“Observations,” 2001), this view was strongly contradicted by a contributor who pointed out "to suggest that people can't learn without human interaction would suggest that people can't learn anything by reading a book in the quiet of a library”. Moore (2000) claims, from experience, that distance learners require a great deal of interaction, although mainly with the purpose of giving reassurance that everything is 'going okay'. According to Michailidou and Economides, (2003) the development of a virtual world motivates students to participate in the educational process by exploring and playing with the lesson material. It can potentially provide an active, independent, student centred and tutor facilitated engagement which enables communication with other students and tutors which may not always be enabled within the traditional classroom setting.

\section{Identification of Critical Success Factors}

The critical success factors in an eLearning environment are different to those in a traditional learning environment. As institutions incorporate elements of online learning into degree courses, many are looking in hindsight at the factors that affect the performance of students who enrolled. The findings of such studies are valuable to those institutions planning eLearning strategies.

A common theme in the findings of such studies was that students who have prior experience of using information technology will generally be more successful in a virtual learning environment than those who do not (Volery \& Lord, 2000). Shabha (2000) extended this line of reasoning by noting that students over the next ten years will come from a wider age range and background and will have a greater variety of education experience. As such, as the rate of technological progress gathers momentum the skill gap widens and the level of training needed to catch up becomes deeper, creating an instant hurdle for those lacking the necessary skills and expertise. For new 
eLearning providers it is important then to accommodate students with little prior experience by offering help. This could be in the form of an initial face to face session teaching students how to access and use courseware and other electronic resources, and could be supplemented with additional help such as 'pop up' boxes in the electronic course material providing students with direction and advice. Volery and Lord (2000) report that the success of the technological infrastructure also has implications for the success of virtual learning, as malfunctioning hardware, software configuration, slow or down servers, busy signals and lack of access are all barriers which can cause frustration for students and ultimately affect the learning process. This issue is difficult to overcome as problems with technology can arise at any time. This challenge is best met by ensuring the functionality of the technological infrastructure before eLearning is implemented.

The lecturer or a course facilitator should be trained as a 'trouble shooter' at a basic level, and be able to resolve elementary hardware and software issues. The instructor is also a major factor contributing to the success of eLearning. According to Webster and Hackley (1997) there are three characteristics of instructors that influence student performance: attitude towards technology; teaching style; and control of the technology. Each of these factors should be taken into account in the identification of suitable lecturers, (Volery \& Lord, 2000).

\section{The Importance of Quality Assurance}

Quality assurance is a key issue in the implementation of eLearning (Goddard, 2000) as the number of non-accredited institutions offering degrees increases rapidly, damaging the reputation of online learning (University of Houston, 2000). According to Copeland (2001), a number of virtual programmes have thrown up quality concerns, which in turn means that providers of quality eLearning programmes must fight harder for recognition from employers and the wider society. Empirical evidence on the subject of quality is patchy: a 1999 study of 365 examples of distance education identified 'little or no difference' between the qualities of education received from distance learning compared with the classroom (Caudron 2001), however critics of this new phenomenon are not convinced. The measurement of 'quality' is often qualitative rather than quantitative; personal characteristics acquired/required by online students are used to evaluate the quality of e-qualifications. Caudron (2001) suggests it is possible that online students have to be more disciplined and work harder to achieve their goals, thus implying that e-qualifications must be of a high quality because students must have worked hard to attain them. However, whilst measurable skills can be taught effectively in an eLearning environment, online students lack sufficient immersion and interaction to develop qualitative characteristics such as interpersonal skills - these are still better developed in a high quality traditional setting. It is possible that the quality of eLearning will always be in question, however through implementing rigorous controls, institutions can ensure that students are working to attain credible qualifications, as they would be in a traditional learning environment.

Employers and Humans Resource (HR) professionals have also voiced concerns over the quality of e-qualifications. This means that institutions also have to consider the impact of eLearning on the employment prospects of students. According to a study of 269 HR professionals in September 2000 , 61\% believed that online degrees were not as credible as the traditional qualification (University of Houston, 2001). The major issues for employers are the unknown source of the degree, the lack of student interaction and the high potential for low admission standards into degree courses, says Mark Oldman, co-founder of a New York City career advice firm.

In contrast, some employers place more value in so called 'click and mortar' degrees because they appreciate the hard work, motivation and commitment required to attain a degree online (Caudron, 2001). It is difficult under any circumstances to assess the suitability of a candidate for a job. Students of eLearning institutions should be advised, as are traditional university students, 
that qualities such as experience, enthusiasm, ideas, ability and organisational fit - as well as the degree - all contribute to their overall attractiveness to potential employers (Cauldron, 2001; University of Houston, 2001). Universities should be aware that the implementation of eLearning has implications for job hunting students, however if research is correct (University of Houston, 2001), 'brand name' institutions will soon realise the potential of eLearning and incorporate it into their own programmes. This in turn will convince HR professionals of the value of online degrees, ensuring that e-students are not at a disadvantage to traditional students.

\section{The Implications of eLearning For Lecturers}

\section{Incorporation of New Teaching Styles}

In the implementation of eLearning programmes, HE institutions are demanding a change in the role of university lecturers. Traditional teaching and learning skills need to change in order to get maximum benefit from virtual learning (McFadzean, 2001), hence lecturers are posed with the task of developing a new model of effective teaching. Many researchers have attempted to lay down criteria for successful online teaching, although findings are mixed. McFadzean (2001) concentrates on the psychological aspect of learning, purporting a need to shift from behavioural and cognitive approaches (whereby the lecturer controls the learning) to a humanist approach, where learners can take control of their own learning. The humanist approach suggests that the aim of education is to assist students to achieve self-actualisation and consequently the role of the lecturer shifts from information provider to supporter - encouraging students to feed their own curiosity. The key message here is that students are not spoon fed, but rather shown the way. Moore (2001) extends this basic outline by proposing tactics to get learners to successfully take control. This theory involves splitting distance teaching into three phases of activities: preparation, presentation, and participation and cites examples such as, "attend to student motivation and the affective dimension of being a student... but don't intervene too much. Establish the culture of independent learning and peer participation”.

This student focussed approach is not supported across the board. Research carried out by Learning Peaks (2001) implies that in an online environment the role of a lecturer focuses more on administration than teaching. The Learning Peaks study proposes that the four core competencies of an online lecturer are administrator, facilitator, technical support and evaluator. The need to overcome barriers to successful learning, such as technology and time and place, shifts the core focus away from the needs of the student, towards simply making sure that the course operates smoothly. Whilst it is clear that administrative factors require consideration and action, it seems inappropriate and inadvisable to take the focus away from students, particularly during a period of significant change. The implications of eLearning for lecturers are significant and should not be overlooked by institutions implementing such programmes. Lecturers must be provided with sufficient time and resources to ensure that online courses are suitably developed and implemented to meet the needs of students. Alongside this, the transition into new teaching styles must be managed effectively to ensure that lecturers are supported through and beyond the evolutionary period.

\section{Accommodating Changes in Workload}

Extensive dialogue over the changing role of lecturers has naturally led to concern about the associated changes in workload. Moore (2000) stresses the importance of this pedagogical and political issue and points out that as more lecturers are required to teach in a virtual environment the question of workload climbs ever closer to the top of the distance education agenda. At its simplest, the answer to the workload question might depend on the propensity of the institution to 
employ online teaching and moreover, how well the delivery is organised. However, going further it is clear that numerous factors contribute to the workload of a distance teacher, from the amount of time spent authoring the material, to the level of interaction between student and lecturer. Moore (2000) points out that the issue of workload is directly underpinned by the issue of quality and proposes a minimum 'ballpark' ratio of 50:1, design time to contact time, as well as significant interaction between student and lecturer. This, he purports, will "pay off handsomely in the quality of the learning experience and ultimately the success of the program".

Empirical research into the workload question presents mixed findings and any comparisons must be made carefully due to differences between the various cases that have been studied. Two studies, carried out in 2000 analysed the time taken to teach a course online compared with teaching it in a traditional classroom (Moore, 2000). The findings of the two studies were contradictory. The first reported that distance lecturers experienced a reduced workload: 2.7 hours per student compared to 3.2 hours in a conventional setting, whilst according to the second study, lecturers needed nearly twice as much time to teach an online course compared with a traditional course. This contradiction can be explained by the many differences between the studies, including the subject, student's educational backgrounds and the mix of technologies, thus limiting the generalizability of the comparison, except to highlight that many factors contribute to the workload issue. That is not to say that the studies themselves are not of value - it is very important to analyse cases on an individual basis to identify those variables which contribute to the workload, but also those which contribute to the success of the course. This in turn will allow eLearning providers to ensure that adequate resources are being provided, but that they are also being used effectively.

If the provision of eLearning is to become a key element of university education, employers will need to provide a major programme of staff development and training (Copeland, 2001). Training and support is required to ensure that technology can be integrated into daily routines and that its use will be efficient and effective (Wilson, 2001). However, this too will add to workload pressure, particularly for those requiring significant training due to a lack of experience. This pressure is augmented by the continual need for retraining as lecturers struggle to keep up to date with technological progress and since familiarity with technology has a direct impact on the success of online courses, the importance of training cannot be overstressed.

\section{Summary}

Growth in eLearning is rapid as institutions race to compete for a share of the increased and changing demand for HE. Research suggests that universities failing to embrace technological progress made during the 1990s will be unable to meet the needs of knowledge based societies and as a result will not survive the change in the paradigm of education. However, the implementation of eLearning brings forth implications for all stakeholders in HE, and poses a number of risks which can not be overlooked.

ELearning has a fundamental impact on the structure of HE. Whilst the growth in demand can be accommodated by its implementation, the diversity of the new student population requires that institutions carefully develop programmes that will satisfy a broad range of learning requirements. This challenge is intensified by changes to the competitive environment where, in the wake of lifelong learning, traditional institutions are competing with corporate and virtual universities particularly for the mature student population.

Students are also greatly affected by the implementation of eLearning, principally by the shift in learning styles required to be successful in an online environment. Universities should be aware that dependent learners will require courses tailored to suit their educational needs, potentially 
offering a blend of face to face and virtual interaction. Failure to provide for these needs will lead students to shop elsewhere.

There is a need to acknowledge that active learning within a technologically based environment necessitates the establishment of a theoretical framework as part of the learning process, (Manning, Cohen \& DeMichiell, 2003). This realisation will mean that the use of technology is not about replacing learner process, but enhancement and extension of such. This is most important if we are not to simply 'cut and paste' content, which may have worked in the lecture theatre, in virtual and technology based learning environments.

The critical factors for success will change with the implementation of eLearning programmes: prior experience of using technology; the technological infrastructure; and the lecturer will be the new key elements in the success of the learning experience. HE institutions can help students to achieve success by doing three things. Firstly, a face-to-face session familiarising students with the courseware will help to overcome the issue of prior experience. Secondly, the functionality of the technological infrastructure should be ensured before the course is implemented. This should be backed up by technical support from either the lecturer or a course facilitator. Finally, human resources should be committed to the project at an early stage and lecturers should be selected based on their attitude towards technology, teaching style and ability to control to technology.

For lecturers, eLearning programmes represent a change in teaching style. The precise nature of the change is difficult to quantify, however allocation of sufficient time and resources, combined with managerial support, will help staff through the period of transition. Effective management can also help institutions to deal with any increase in lecturer workload by ensuring efficient use of resources

ELearning offers HE institutions all the benefits of a global consumer base. In order to reap these benefits, universities should carefully assess the implications of eLearning. Programmes should be of high quality and should meet the needs of the diverse student population. This should ensure the success of eLearning into the future, providing institutions with a much needed competitive edge.

\section{References}

Bourner, T. \& Flowers, S. (1997). Teaching and learning methods in higher education: A glimpse of the future. Reflections on Higher Education, 9, 77-102.

Brewer, S. (1998). Online connections. Home PC, 5 (4), 117.

Caudron, S. (2001). Evaluating e-degrees. Workforce, 80 (2), 44.

Currie, J. (1999, November 5). Digital age leaves professors talking turkey. Times Higher Education Supplement.

Cooper, T. (1999). Whose academy is it? New Statesman, 128 (4460), xxvi

Copeland, R. (2001, May 18). The usual rules apply online. Times Higher Education Supplement.

Daniel, J. (1996). Mega universities and knowledge media. London: Kogan Page.

Davies, D. (1998). The virtual university: A learning university. The Journal of Workplace Learning, 10 (4), $175-213$

Lessons of a virtual timetable: The promise of online education. (2001, February). Economist US.

Lifelong learning and the virtual university. (1998). Education and Training, 40 (4), 141-142.

Goddard, A. (1998, November 13). Facing up to market forces. Times Higher Education Supplement.

Goddard, A. (2000, June 16). Big brands key to e-university. Times Higher Education Supplement. 
Hawkes, M. \& Cambre, M. (2000). The cost factor. Technological Horizons in Education, 28 (1), 26.

Hoare, S. (2001, February 21). E-courses: Net that degree. The Guardian, p. 41

Johnston, C. (2001, August 31). Learners must play leading role. The Times Higher Education Supplement.

Katz, R. (2001, May 18). Campus champs tackle heavies. Times Higher Education Supplement.

Kershaw, A. (1996, September/October). People, planning, and process: The acceptance of technological innovation in post-secondary organizations. Educational Technology, 44-48.

Knight, P. (Ed). (1996). Assessment for learning in higher education. London: Kogan Page, SEDA Series.

Learning Peaks. (2001). Asynchronous online learning instructor competencies. Retrieved November $6^{\text {th }}$, 2003 from www.insighted.com/instrcomp.html

Manning, R., Cohen, M., \& DeMichiell, R. (2003). Distance learning: Step by step. Journal of Information Technology Education, 2, 115-130, Retrieved from http://jite.org/documents/Vol2/v2p115-130-96.pdf

McFadzean, E. (2001). Supporting virtual learning groups. Part 1: A pedagogical perspective. Team Performance Management, 7 (3,4), 53-62

Michailidou, A., \& Economides, A. (2003). Elearn: Towards a collaborative educational virtual environment. Journal of Information Technology Education, 2, 131-152. Retrieved from http://jite.org/documents/Vol2/v2p131-152-92.pdf

Moore, M. (2000). Is distance teaching more work or less? The American Journal of Distance Education, $14(3)$.

Moore, M. (2001). Surviving as a distance teacher. The American Journal of Distance Education, 15 (2).

National Committee of Enquiry into Higher Education. (2001a). Report of the National Committee. Retrieved October $26^{\text {th }}$, 2003 from www.leeds.ac.uk/educol/ncihe/natrep.htm

National Committee of Enquiry into Higher Education. (2001b). National Report. Chapter 13: Communications and Information Technology. Retrieved November $4^{\text {th }}, 2003$ from www.leeds.ac.uk/educol/ncihe/nr_202.htm

O’Donoghue, J. \& Singh, G. (2001). A study of social-learning networks of students studying an on-line programme. International Conference on Advanced Learning Technologies (ICALT). Madison, Wisconsin USA.

Observations of a Telecommuter; Ethics and the Bottom Line; Customer Service That Teaches; What's a Learning Executive? New Column! Scoping the E-Learning Market. (2001). Training and Development Journal, 55 (7), 6.

Paton, N. (2001, October 13). Why bright sparks take the e-way. The Guardian, p. 24.

Pollock, N. \& Cornford, J. (2000). Theory and practice of the virtual university. Ariadne, 24. Retrieved November 5, 2003 from www.ariadne.ac.uk/issue24/virtual-universities/

Pritchard, A. L. \& Jones, D. R. (1996). Global learning. Open Learning Australia. Retrieved April 13, 2004 from http://www.ola.edu.au/paper1.htm

Redfern, S. \& Naughton, N. (2002). Collaborative virtual environments to support communication and community in Internet-based distance education. Journal of Information Technology Education, 1 (3), 201-211. Retrieved from http://jite.org/documents/Vol1/v1n3p201-211.pdf

Shabha, G. (2000). Virtual universities in the third millennium: An assessment of the implications of teleworking on university buildings and space planning. Facilities, 18 (6), 233-244

Singh, G. \& Priola, V. (2001). Long distance learning and social networks: An investigation into the social learning environment on online students. Proceedings of the Sixth Annual ELSIN Conference. 158-164.

University of Houston. (2000). Societal Views of Online Degrees. Topics on Distance Education. Retrieved November 7, 2002 from www.atlantis.coe.uh.edu/detopics/society.htm 
Volery, T. \& Lord, D. (2000). Critical success factors in online education. The International Journal of Education Management, 14 (5), 216 - 223.

Webster, J. \& Hackley, P. (1997). Teaching effectiveness in technology-mediated distance learning. Academy of Management Journal, 40 (6), 1282-1309.

Wilson, G. (2001). The promise of online education: El Dorado or Fool's Gold? The Educational Technology Journal, 11 (1).

\section{Biographies}

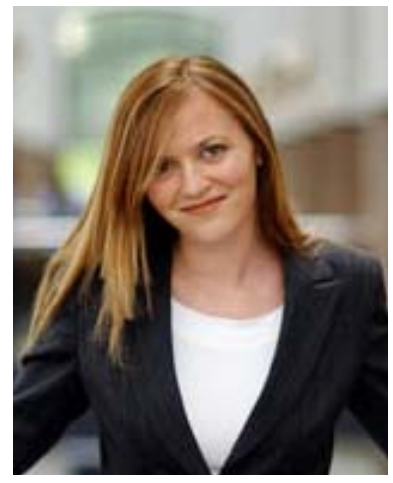

Kayte O'Neill has worked on a variety of projects ranging from the impact of emerging technologies on the transmission business, to analysing the activities of external players within the UK power market. Kayte has developed a keen interest in the implications of new technology for all areas of the business community, culminating in a research study which has explored the impact of technologies in organisational structures and management.

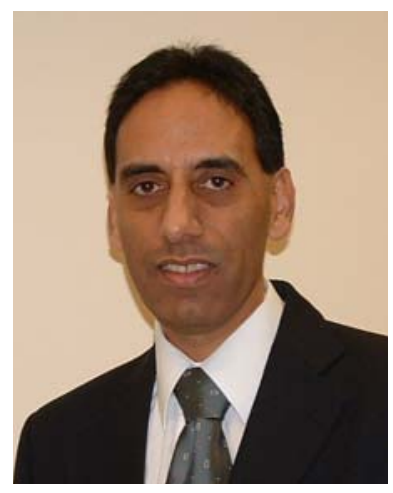

Gurmak Singh is a subject leader for Finance and Information Management within the Business School at the University of Wolverhampton. His primary research thrust involves social learning facets of designing teaching and learning software. He has developed material to be delivered in an online format and is keen to consider the implications of learning remotely.

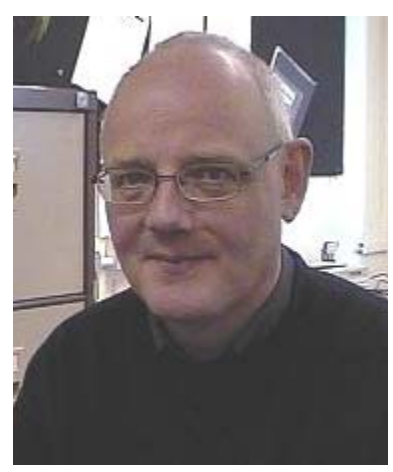

John O'Donoghue has a wide range of educational experiences: teaching, lecturing, advising, consultancy and research. He holds a number of fellowships and honorary positions, including a visiting research fellowship at a University in Australia. For many years an advocate of the 'global classroom', John continues to write and publish extensively on the use and exploitation of the information in information technology. In his present post, he is responsible for the academic and pedagogical aspects of networked learning technologies with special emphasis on the education and training sector. 